
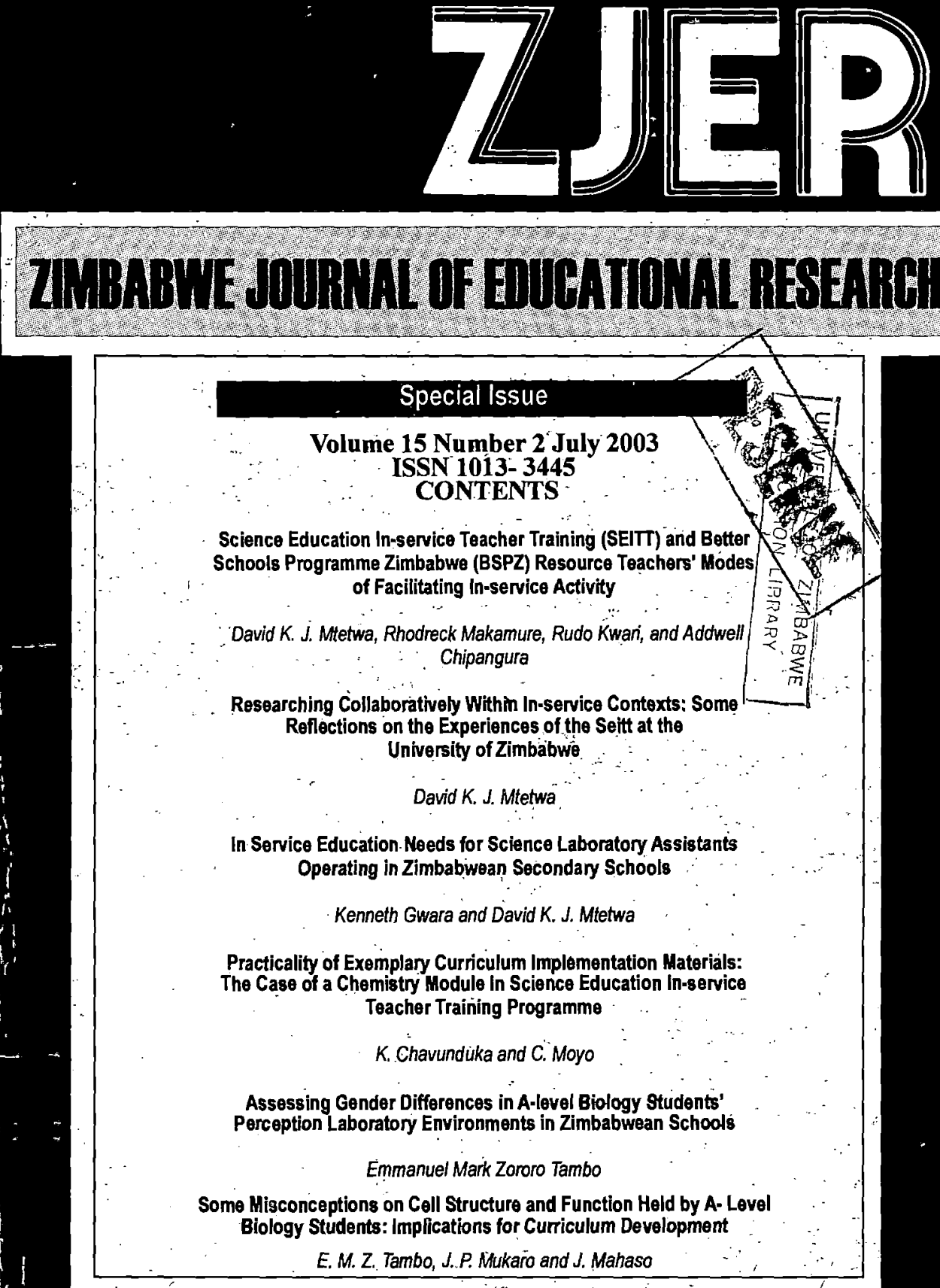


\title{
IN-SERVICE EDUCATION NEEDS FOR SCIENCE LABORATORY ASSISTANTS OPERATING IN ZIMBABWEAN SECONDARY SCHOOLS
}

\author{
Kenneth Gwara and David K.J. Mtetwa
}

\section{Abstract}

The study sought to idlentify the kinds of knowledge and skills possessed by or lacking in persons serving as laboratory assistants in Zimbabwean schools in relation to their effective functioning. Data was obtained through focussed group discussions and questionnaires within the framework of a national survey. The informants were 124 designated laboratory assistants, 79 heads. of science departments from different high schools and regions and 9 science education officers. The main finding was that these assistants require inservice education in basic repair and service of equipment, preparation of chemical solutions, general laboratory management skills, and safety and calibration of equipment.

\section{Research Problem}

Good science teaching at any level has to be laboratory based. Besides being well-stocked with appropriate laboratory hardware, software, and consumables that science teachers can use for their teaching, a good laboratory also requires management services of a laboratory attendant, commonly called laboratory/lab assistant. No laboratory can function effectively without a lab assistant, whose functions are to:

organise practical classes;

service and maintain equipment;

improvise equipment and other needed materials;

prepare chemical solutions;

manage the overall laboratory èvironment. (Njoku, 1994; Ogunniyi, 1977; and www.lifee.sci.qit.edu).

In principle, all secondary schools in Zimbabwe have at least one laboratory for science teaching. Hence, they should have at least one lab assistant. 
Whether that is the case in practice would indeed be an interesting issue to investigate. The investigation reported in this paper focuses on the nature of laboratory maintenance competences that those persons designated as lab assistants possess, or at least, should possess.

It is common knowledge that most secondary schools in Zimbabwe are seriously under-equipped, and those that could be considered as equipped, are stocked with largely dated or broken down materials that need repair (Carelse, 1981). It is also well-known that in many secondary schools, the person who serves as laboratory assistant is basically a general laboratory hand with little science education and without the appropriate training as a lab assistant such as that offered at technical colleges or polytechnics (Hodzi, 1993). In fact, most of them are $\mathrm{O}$ - or A-level graduates who have failed to move on with their chosen career paths and have simply been appointed by the school head to assist science teachers with maintaining the laboratory. Occasionally, one may find those with Zimbabwe Junior Certificate as their highest qualification or those that found themselves in the lab on promotion from being general hands on school grounds. The main observation to note here is that while the backgrounds of these laboratory assistants is certainly as varied as the routes through which they found themselves as laboratory assistants, they are nevertheless all serving in the capacity of laboratory assistants or technicians. It has also been observed that many of these lab assistants do not professionally further develop themselves as laboratory assistants. Instead they develop themselves into different careers such as marketing and bookkeeping.

Given such a profile of lab assistants one sees in many secondary schools, an interesting question is: "What knowledge and skills relevant to the task of maintaining and running a science laboratory do these assistants posses?" The question becomes even more urgent in view of the current thrust in science teaching which emphasises the development of experimental and other practical skills in students. This emphasis is motivated by two movements:

- the current interest by science educators and curriculum developers in issues of assessing science practical knowledge and skills, and;

- the popularisation of contextualised-driven teaching approaches among science teachers.

This latter movement is being spearheaded by the Science Education In-service Teacher Training (SEITT), an in-service education programme for science and maths teachers as conceptualised by the Department of Science and Maths 
Education (DSME) at the University of Zimbabwe and implemented in collaboration with the Ministry of Education, Sport and Culture, and the Royal Netherlands Embassy. SEITT promotes active learning of concepts, which translate into an emphasis on practical and experimental activity reflected in contextualised instructional materials that the programme encourages teachers to develop and use.

'The research question for the study, therefore, was: "To what extent do secondary school science laboratory assistants posses knowledge and skills that are essential for their work?"

\section{Data Generation}

Data were obtained from a total of 79 heads of science departments, 9 education officers, and 124 laboratory assistants from schools that accepted invitations to attend workshops on laboratory equipment production. Of the 10 educational regions in the country at the time, only Mashonaland East region did nót participate in this series of workshops due to technical problems that emerged at the time. The workshops were planned and conducted by the two teclnicians in the Department of Science and Mathematics Education at the University of zimbabwe. One workshop was held at the Science and Mathematics Centre (SMC) in each of the 9 educational regions that participated.

The following procedure was used to get workshop participants to the SMC. Invitation letters for the workshops were prepared by the SEITT team and given to each region's education office. The science and mathematics education officer in that office would then put an official stamp on each letter and transmit the letter to all the A-level high schools in that region.

Where necessary the education officer would follow up with telephone calls to school heads to confirm that the school's head of science department and his/ her senior laboratory assistant were invited to attend a workshop at the SMC. The SEITT project met all the travel and food expenses for the participants.

The three-hour workshop began with registration of participants, followed by an introductory review' of the programme by the education officer for the region or the SMC manager. The Department of Science and Mathematics Education's SEITT technician then discussed the theme of the workshop, which was in all cases, to design an in-service programme for school laboratory assistants. A question and answer session followed. During that session, the assistant researcher (the other DSME technician) would record the questions 
asked and the reactions elicited by the question. This focussed group discussion provided one set of data on laboratory assistants' needs for in-service education.

After this first phase, there was a tea break that was followed by a second phase consisting largely of questionnaire completion. The questionnaire for the laboratory assistants had three sections. Section A captured demographic data, Section B focussed on their knowledge of basic laboratory skills, and Section $C$ assessed their capacity to improvise, service, and repair simple laboratory equipment.

The response scale for each iten had the following options:

- I have a good command and experience of laboratory hardware and software or consumables and have received proper training in this particular aspect/issue/skill.

- I have adequate experience with the particular aspect/issue/skill.

- I have an idea of how to do (the aspect/issue/skill) but I need proper assistance.

- I need in-service training for the skill/aspect/issue.

The questionnaire for the school heads, heads of science department (HODs), and education officers (EOs) was similar to the one for laboratory assistants. It had a section that required the respondents to indicate laboratory skills that they expected their laboratory assistants to possess and the aspects where they judged their assistants to require further training. The respondents had to rate their laboratory assistants' competency levels in repair and service skills. Each item had to be rated using the three-point scale of:

Very Good:- if the assistant was well trained and had good command of the knowledge entailed by his/her job, was dependable, and could work under minimum supervision.

Good:- if the assistant was dependable and fairly experienced but needed close supervision though he/she could leain things quickly.

Poor:- if the assistant did not appear to learn and gain from experience, did not grasp things quickly, was not dependable, and required training.

The final section of the questionnaire was open-ended and sought the respon- 
dents' suggestions on the nature of intervention needed to assist their laboratory assistants become more effective in their work.

All the quantitative data was analysed for frequency patterns while the textual data was analysed for recurrent themes.

\section{Data Analysis}

\section{Table 1: Laboratory Assistants Questionnaire}

Item

$$
\begin{aligned}
& \text { Number in need Percentage } \\
& \text { of training } \\
& (N=124)
\end{aligned}
$$

\section{Section B- Basic Skills}

1. identify apparatus by name and function

2. recognise chemical symbols

3. equipment handling

4. collection of specimens for practicals

5. preparation of chemical solutions

6. (i) titration

(ii) measuring mass of objects

(iii) reading of venier scales

63

7.calibration of instruments e.g, $\mathrm{CRO}, \mathrm{pH}$ meters etc.

8. laboratory environmental hazards e.g., split mercury

9. first aid to accident victims

\section{Section C - Service \& Repair}

1. wiring plugs

2.reading equip. manuals and installation instructions

3. improvisation of equipment

4. preparation of permanent bio-slides

5. glass blowing techniques

6. repair and service of electronics equipment

7. use of the environment to improvise

8.dissection and preservation of biological specimens

9. unblocking pipettes and burettes 10.service of mechanical equip e.g., boss heads and stands

$\begin{array}{rr}37 & 30 \\ 99 & 80 \\ 93 & 75 \\ 121 & 98 \\ 72 & 58 \\ 74 & 60 \\ 69 & 56 \\ 73 & 59 \\ 62 & 50 \\ 64 & 52\end{array}$


Table 2: Science H.O.Ds, E.Os and School Heads Questionnaire

Item

Number that saw

$\%$

the need to train

the laboratory

assistant

$(\mathrm{N}=\mathbf{8 9})$

\section{Section A: Basic Skills}

1. general care and lab maintenance

2.handling delicate equipment and storing in a proper way.

3. setting up equipment and materials for a session 59

4. identifying laboratory apparatus by their name and function

5. setting and pre-testing demonstrating equipment. 80

6. collecting specimens from the environment.

7.preparing biological preservatives and preserving specimens.

8. cleaning of microscopes and optical instruments 51

9. using chemical and weighing balances

10. preparing chemical solutions when given

specifications without supervision.

\section{Section B: Construction and Repair of Equipment}

1. connecting electrical wires to plugs

2. repairing simple electronic equipment, e.g.,

ammeters, power suppliers galvanometers, etc.

3.calibration and use of digital instruments such as

e.g., peri-scopes, pin-hole camera

5. preparation of permanent slides

6.use of glass tubes to form various kinds of delivery tubes

\section{7. recharging wet cell batteries}

8.repairing simple apparatus like unblocking pipettes and burettes. 
Table 3: Focused Group Discussions and Open-ended Responses from the Questionnaires

Recurrent Themes

\author{
Number that saw Percentage \\ the need to \\ train as assistant \\ $(\mathrm{N}=89$ )
}

1. ' need to identify apparatus and know their use

80

2. need to be taught how to prepare chemicals and observe appropriate safety precautions

86

3. need to be taught basic repair and calibration

of equipment skills

86

97

4. need to have a basic theoretical background of practicals in order to assist with practicals demonstrations.

5. need to learn general laboratory management skills

52

6. need for frequent in-service in-order to keep pace with technology

\section{Discussion}

From Table 1, it can be noted that over $60 \%$ of the laboratory|assistants indicated they are in need of training on a number of critical areas like preparation of chemicals, calibration of equipment and reading of venier scales. The indication that the lab assistants perform poorly on such competencies inplies that science teachers cannot assign the laboratory assistant to prepare for practicals during his/her absence. In addition, the teachers would not have confidence to leave the laboratory assistant supervising the students in the laboratory as they have poor skills in laboratory safety, environmental hazards, and even giving first aid to laboratory accident victims.

The second part of the table, which is for service and repair skills, indicates that the laboratory assistants are seriously in need of training on these aspects. The observation that the laboratory assistants perform badly on construction and repair skills implies that unless the teacher him or herself improvises or repairs broken down equipment, the laboratory assistant may not be helpful in that regard.

Table 2 (Questionnaire for HODs and EOs ) indicates in Section $\mathrm{A}$ that the science teachers and the science EOs support training of the laboratory assis- 
tants on a number of critical competencies such as, general care and laboratory maintenance, preparation of chemical solutions, use of laboratory equipment and the skills of setting up for practicals or demonstration sessions. The main observations on areas of need coming out from this section are consistent with what is indicated by the laboratory assistants in table one. However, from the section $B$ of the second questionnaire the science HODs and the science EOs have also suggested that the laboratory assistants are quite handicapped in construction and repairing skills hence they need appropriate in-service training.

In Table 3, which sumnarises open-ended responses from both the questionnaire for HODs and EOs and the focused group discussions, recurrent themes also indicate that there is a great need to have the laboratory assistant trained especially in such aspects as repair and calibration of equipment, preparation of chemical solutions and general laboratory management skills.

\section{Conclusion}

The findings of this study have important implications for the training of laboratory assistants in all secondary and high schools in Zimbabwe. The selfrating inventory by the laboratory assistants has indicated that their areas of greatest need of help are in repair and construction of equipment as well as in the preparation of chemical solutions. Therefore there is need to develop a training course for the laboratory assistants that will enhance their competencies.

\section{References}

Hodzi, R.A. (1993). Innovative ideas and techniques for science educators. in Africa: The Harare generator: International Centre for Conservation Education on behalf of International Council of Scientific Unions.

Njoku, C. Z. (August, 1994). An assessment of job related competencies possessed by school science laboratory assistants: Implications for in-service. training. Journal of the Science Teachers' Association of Nigeria, 29(I \& 2), $55-64$.

Ogunniyi, M.B. (1977). Status of practical work in ten selected secondary schools in Kwara State. Journal of the Science Teachers'Association of Nige- 
Zimbabwe Journal of Elucational Research ria, 19(3), 71-77.

www.life.sci.qit.edu. 


\section{(c) (1) (9)}

This work is licensed under a

Creative Commons

Attribution - NonCommercial - NoDerivs 3.0 License.

To view a copy of the license please see:

http://creativecommons.ora/licenses/bv-nc-nd/3.0/ 